\title{
"Los forjadores de hombres": Disputas por el control de las escuelas y el espacio público en comunidades mineras mexicanas, 1917-1978
}

\author{
"Os forjadores de homens": Disputas pelo controle das escolas e pelo espaço \\ público em comunidades mineiras mexicanas, 1917-1978
"The makers of men": Fight over Control of School and Public Spaces in Mexican Mining Communities, 1917-1978.

\author{
RENÉ MEDINA ESQUIVEL ${ }^{1}$
}

\section{Resumen}

El proyecto educativo de los gobiernos posrevolucionarios tuvo especial importancia en el proceso de consolidación del nuevo Estado y en establecimiento de una alianza con los trabajadores de la minería, a fin de disputar el control de esta industria a las grandes empresas trasnacionales. La Constitución mexicana de 1917 eliminó la concepción liberal de las leyes y restableció el principio de dominio y propiedad de la nación sobre los bienes del subsuelo. Pero el Estado mexicano tuvo que emprender una larga lucha para disputar a las empresas extranjeras el control sobre aspectos económicos, laborales, tributarios y sociales de la minería. El propósito de este trabajo es mostrar esta relación conflictiva en el marco de las comunidades mineras como ámbito de disputas por el control de las escuelas y el espacio público.

Palabras clave: Proyecto de enclave, proyecto nacionalista posrevolucionario, comunidades mineras.

\footnotetext{
${ }^{1}$ Doutor em Ciências na Especialidade de Investigações Educativas pelo Departamento de Investigaciones Educativas del Centro de Investigación en Estudios Avanzados (Instituto Politécnico Nacional). Professorpesquisador da Divisão de Estudos de Pós-Graduação da Benemérita y Centenaria Escuela Normal del Estado de San Luis Potosí. E-mail: renemesqu@ hotmail.com
} 


\title{
Resumo
}

O projeto educativo dos governos posrevolucionairos tiveram especial importancia no proceso de consolidação do novo Estado e no estabelecimento de uma aliança com os trabalhadores da mineiração, a fim de disputar o controle desta industria às grandes empresas transnacionais. AConstituição mexicana de 1917 eliminou a concepção liberal das leis e restabeleceu o principio de dominio e propriedade da nação sobre os bens do subsolo. Mas o Estado mexicano teve que emprender uma longa luta para disputar com as empresas estrangeiras o controle sobre aspectos económicos, laboráis, tributarios e sociais da mineiração. O propósito deste trabalho é mostrar esta relação confitiva no marco das comunidades mineiras no âmbito de disputas pelo controle das escolas e o espaço público.

Palavras-chave: Projeto de "enclave", projeto nacionalista posrevolucionario, comunidades mineiras.

\begin{abstract}
The Education Project of the Post-revolutionary Government was especially important in the consolidation of the new State. Using the education project, the Government established an alliance with the mining workers to fight for the control that the great transnational companies wanted. The Mexican Constitution of 1917 eliminated the concept of liberal laws, and reestablished the principle of national domain and property of the subsoil goods and chattels. The Mexican State had to fight a long battle to dispute the control of economic, work, social, and tributary aspects of mining, with foreign companies. The purpose of this paper was to present the conflictive relationship between the Government and the transnational companies. The mining communities were the realm of dispute over control of schools and public spaces.
\end{abstract}

Key Words: "Enclave” Project, National Post-revolutionary Project, Mining Communities. 
Este trabajo tiene el propósito de contribuir a la comprensión de las tensiones y disputas en torno de la producción del espacio público y los sentidos de la educación acontecidos entre el Estado mexicano posrevolucionario y los consorcios trasnacionales en comunidades mineras mexicanas. Para ello ofrezco primeramente un esbozo general de la forma en que los consocios mineros trasnacionales operaron en México en el marco de las políticas económicas que antecedieron a la Revolución de 1910 y la forma en que implementaron su proyecto de enclave en las comunidades mineras. Posteriormente abordo las transformaciones legislativas surgidas a partir de la promulgación de la Constitución de 1917, así como las reacciones de las trasnacionales mineras ante este nuevo panorama legal. Durante la etapa de enfrentamiento entre el proyecto empresarial de enclave y el proyecto nacionalista del Estado mexicano, en alianza con los trabajadores, ambas partes se disputaron el control de las escuelas y los espacios públicos de los centros mineros. En el periodo de defensa del proyecto de enclave, los consorcios trasnacionales aprovecharon la coyuntura de la Segunda Guerra Mundial para recuperar antiguos privilegios, mientras que el Estado mexicano transformó sus políticas en detrimento de su alianza con los trabajadores. Finalmente, durante el periodo de "mexicanización de la minería" el Estado impulsó nuevas leyes y políticas, participó como empresario en esta actividad, fortaleció su presencia en las comunidades mineras a través de agencias gubernamentales e intervino en el sindicalismo minero con el fin de aumentar su margen de control sobre este gremio.

La educación y la escuela son lugares donde se forja la nación, por ello han ocupado un papel protagónico en el proceso de legitimación de todo grupo que toma el poder; tarde o temprano los nuevos regímenes revolucionarios descubren en ellas el medio idóneo para interiorizar su agenda ideológica en los ciudadanos comunes (Rockwell 2007,12-16). Pero la implementación de las políticas del Estado es un proceso complejo, cruzado por diversidad de sujetos que entablan disputas por los sentidos de la educación y la construcción del espacio público. Si bien los consorcios mineros y el Estado mexicano son los personajes más documentados y sobre los que más se informa en las fuentes consultadas para este estudio, los ciudadanos comunes y diversidad de poderes locales participaron activamente en las disputas que aquí analizo. El espacio público es más que un escenario donde ocurren las disputas, es más bien el resultado y condición de las intervenciones económicas, políticas e intelectuales de quienes luchan por los sentidos de la historia y, por eso mismo, los sentidos de la educación.

\section{1. "Nosotros, los forjadores de metal": El proyecto empresarial de enclave y las comunidades mineras.}

México obtuvo su independencia en 1821 tras once años de guerra que generaron una disminución en la actividad minera. El nuevo gobierno promulgó leyes que favorecieron la inversión extranjera en 1823, éste y otros factores contribuyeron a que la minería entrara en una fase de recuperación (Bernstein, 1964). Durante las décadas siguientes, las inversiones británicas predominaron, seguidas por las alemanas y estadounidenses. No obstante, la inestabilidad política de México, las guerras constantes y la falta de certeza jurídica en lo relativo a la posesión de los fundos mineros limitaron la participación de los capitales extranjeros. 
Autores como Bernstein (1964) y Sariego el al. (1988) coinciden en que el gobierno mexicano adoptó el liberalismo como política económica desde mediados del siglo XIX y que esos principios se plasmaron en la Constitución de 1857. Sariego el al. (1988) señalan que las leyes de 1884 y 1892 fueron los códigos más liberales en la historia de la minería mexicana puesto que otorgaron a los particulares la propiedad de los recursos del subsuelo a costa de modificar el viejo régimen de propiedad y dominio directo de la Nación sobre esos recursos. Estas nuevas circunstancias favorecieron el establecimiento de grandes monopolios mineros de capital estadounidense en detrimento de los antiguos empresarios españoles, mexicanos y europeos. Hacia finales del siglo XIX, grandes consorcios mineros como la American Smelting and Refining Company (ASARCO), la Cananea Consolidated Copper Co. S. A. y la American Metal Co. S. A. se establecieron en México al amparo de las nuevas leyes y de la concesión de garantías y privilegios extraordinarios como las exenciones de impuestos y el beneplácito de los diferentes niveles de gobierno para que las empresas dictaran las políticas económicas, laborales, sociales y hasta tributarias que habrían de regir su actividad (Sariego et al. 1988: 1231). Bajo estas condiciones, las empresas mineras estadounidenses realizaron grandes inversiones en territorio mexicano, emprendieron un incipiente proceso de modernización de esta actividad y establecieron redes ferroviarias que conectaban a los centros de extracción con las fundidoras y los proveedores de insumos como madera, leña, carbón y chapopote (nombre local dado al asfalto). Los antiguos productores mineros no resistieron esta competencia, de tal forma que tendieron a incorporarse a los nuevos mercados o a desaparecer.

El presidente Porfirio Díaz estableció un régimen de gobierno que detentó el poder entre 1877 y 1911 y que se autoproclamó como progresista, moderno y civilizado. Si bien se atribuye al porfiriato el logro de una paz duradera, estabilidad política y prosperidad económica; también se ha cuestionado la violencia con que Díaz reprimió a toda disidencia u oposición, así como el logro de una bonanza económica que benefició tan solo a las élites del país mientras que la mayoría de la población vivía en precarias condiciones económicas y sociales (Knight, 1986). En lo relativo a la educación, este régimen impulsó un sistema de escuelas primarias orientado fundamentalmente a las zonas urbanas, mientras que el medio rural y las grandes masas de pobres en las ciudades quedaron segregados de ese proyecto educativo. El analfabetismo apenas disminuyó en menos de un $10 \%$ a lo largo de todo el régimen porfirista, mientras que las inversiones en educación superior beneficiaron a reducidas élites y proveyeron a los inversionistas extranjeros de profesionistas para la industria $^{2}$. Dadas estas circunstancias, el proyecto porfiriano de educación y modernidad llegó sólo a un reducido porcentaje de la población (Loyo y Staples, 2010: 127-129).

Bernstein considera que el porfiriato generó las condiciones de certeza jurídica y estabilidad para la inversión extranjera y la industrialización de la minería, lo que constituyó un nuevo periodo de profundas transformaciones en esta actividad (Bernstein 1964: 8-14). El porfiriato entregó a los inversionistas extranjeros las riquezas del subsuelo mexicano y continuó otorgándoles toda clase de estímulos, exenciones y privilegios; pero además puso a su disposición una mano de obra sumamente barata y poseedora de una tradición laboral minera con la libertad de dictar políticas a voluntad; todo ello a cambio de una exigua recaudación tributaria. Los consocios mineros se adjudicaron la facultad de controlar lo que ocurría dentro y fuera de los centros de trabajo:

\footnotetext{
${ }^{2}$ En 1888 el porcentaje de personas que no sabían leer ni escribir era de 80\%, mientras que al final del gobierno de Díaz este porcentaje superaba el 70\%. La modernidad porfiriana impulsó la fundación de nuevas carreras, la mayoría de ellas, técnicas (Loyo y Staples, 2010: 136-154).
} 
Durante el porfiriato el Estado delegó muchas atribuciones de su política laboral en los empresarios extranjeros, bajo cuya iniciativa quedó la reglamentación de los sistemas de contratación y estabilidad en el trabajo, la seguridad minera, fijación de condiciones de trabajo y salarios y, en general, la determinación de las condiciones de atención a la salud, la educación y el ocio de los trabajadores mineros (Sariego et al. 1988: 15).

Los industriales mineros establecieron nuevos asentamientos productivos constituidos como verdaderos enclaves, donde poseían amplias facultades para dictar normas y controlar incluso a las autoridades locales sin la intervención de los gobiernos federal ni estatales. Aunque estas empresas se asentaron también en antiguos reales de minas, sólo lograron establecer márgenes de control que dependieron de las tradiciones mineras preexistentes, la ubicación geográfica de esos asentamientos y la diversificación de actividades económicas. Los centros de producción aislados y lejanos ofrecían las condiciones óptimas para que los consorcios mineros rigieran la vida comunitaria fuera de los espacios laborales. Sariego et al. designan a este modelo de control empresarial como "proyecto de enclave" y señalan que los capitalistas extranjeros lograron imponerlo desde la última década del siglo XIX hasta finales de la década de 1920.

Autores como Sierra (1990), consideran que estas políticas de paternalismo industrial constituyen más que un mero afán de control político y social, pues las consideran como un amplio proyecto internacional del empresariado encaminado a la reproducción social de una mano de obra ideal para las actividades productivas en diversas industrias. ${ }^{3}$ El paternalismo industrial consistió en una estrategia patronal de intervención y control de la vida de sus trabajadores más allá del ámbito laboral. Sierra (1990) plantea que desde mediados del siglo XIX un segmento importante de los patrones capitalistas implementó estrategias para "intervenir tenaz y duraderamente en la vida -y no sólo en el trabajo- de los obreros, de sus obreros" (Sierra, 1990: 3), con el fin de formar a sus trabajadores y educar a las nuevas generaciones de acuerdo con un modelo ideal de ciudadano-obrero. Estos empresarios llevaban a cabo obras sociales como construcción de viviendas por iniciativa empresarial, almacenes patronales, economatos y cooperativas, escuelas, templos, orfeones y círculos obreros, entre muchas otras. A través de estas obras, los patrones buscaban influir sobre los trabajadores y sus familias, adquirían ante ellas la categoría de benefactores y propagaban su ideología. En el México de finales del siglo XIX, los grandes consorcios mineros daban una importancia central al establecimiento de servicios para sus trabajadores, se proponían el control sobre el diseño de un espacio público estratificado y provisto de hospitales, escuelas, agua potable, electricidad, actividades de recreación, etc. Sin embargo, estas obras sociales estaban al servicio de los intereses empresariales, ya que tenían como fin contribuir a la formación de una clase obrera apta para el trabajo industrial y mantener un amplio control de las comunidades mineras como enclaves libres de la intervención del Estado.

\footnotetext{
${ }^{3}$ En El obrero soñado: Ensayo sobre el paternalismo industrial (Asturias, 1860-1917), Sierra analiza políticas empresariales semejantes en la industria minera asturiana y muestra al paternalismo industrial como un programa ideológico-moralista de largo alcance elaborado por el primer empresariado capitalista (Sierra, 1990).
} 
Los consorcios mineros norteamericanos crearon la revista Engineering and Mining Journal (E\&MJ) en 1866 con la finalidad de contar con un medio de intercambio y difusión de asuntos técnicos, económicos, sociales y políticos de interés para el alto empresariado minero de todo el mundo. ${ }^{4}$ En estas publicaciones, los empresarios expresaban que las escuelas para los trabajadores y sus hijos eran centros formadores de buenos obreros y de mejores ciudadanos; y que la introducción de servicios sanitarios y medicina moderna redundaba en la generación de mujeres y hombres más sanos, vigorosos y aptos para las tareas de producción y reproducción social. En 1918, un alto inversionista publicó un texto donde planteaba las responsabilidades y compromisos de los empresarios para con los trabajadores y familias que vivían en los campos mineros. Según el texto "Bienestar en los centros mineros y la generación futura", era responsabilidad suya y de sus homólogos: a) la creación de campos mineros que funcionaran como verdaderos centros de bienestar, b) la provisión de una buena educación para niños y niñas, c) la formación y la recreación de los trabajadores y sus familias más allá de los espacios laborales y c) la dotación de infraestructura para salud, recreación, arte y deporte. Este empresario expresaba textualmente "Nosotros, los forjadores de metal, debemos llegar a ser también los forjadores de hombres. Nosotros, quienes tenemos el futuro en nuestras manos, debemos construir profundamente comenzando por los niños". 5

El proyecto educador de los industriales mineros no sólo se llevaba a cabo a través de las escuelas, el diseño de los espacios públicos estaba pensado para generar hombres y mujeres más saludables y productivas debido a una cuidadosa planeación de las condiciones sanitarias modernas. Además, la distribución del espacio público servía para adentrar en sus moradores una concepción del lugar que les correspondía dentro de un esquema jerárquico derivado su condición étnica y su rol en la división del trabajo. Sariego (1994) analiza la forma en que las empresas diseñaban los espacios públicos en los enclaves mineros: primeramente monopolizaban la propiedad de la tierra y de los recursos urbanos, organizaban los espacios con una lógica segregacionista que mantenía separados a los mandos extranjeros de los trabajadores, proveían de servicios y espacios de recreación bien diferenciados para cada estrato o barrio del asentamiento:

Calles, plazas, mercados, templos, colonias, viviendas, escuelas, comercios tiendas de raya, hospitales, clínicas, cines, teatros, clubes, campos deportivos y centros de ocio, todos ellos erigidos por iniciativa patronal, sirvieron para separar a los directivos y mandos superiores extranjeros de los trabajadores, e incluso a estos entre sí, de acuerdo con su nacionalidad, condición étnica o categoría laboral (Sariego, 1994: 331).

\footnotetext{
${ }^{4}$ Esta revista brinda la posibilidad de conocer diversos aspectos de la actividad minera industrial, entre ellas las políticas laborales de las empresas y las finalidades con que el alto empresariado las ponía en práctica. E\&MJ se continua publicando hasta el presente: McGraw-Hill, Engineering and Mining Journal. Mining's Dynamic Age. Centennial Issue 1866-1966, Mc Graw-Hill Publications, New York, 1966.

5 "Mining-Camp Welfare and The Future Generation". Nevada City, California, 18 de mayo de 1918. Engineering and Mining Journal, Vol. 105, 1918, 1 de septiembre de 1918, p. 1131. Mi traducción.
} 
Las publicaciones de los empresarios en la E\&MJ dejan claro que éstos asumían una cierta responsabilidad por el bienestar dentro de los campos mineros, también revelan que se adjudicaban el derecho de mantener el control sobre estos espacios y las obras sociales que realizaban. Pero la Revolución mexicana y la promulgación de la Constitución de 1917 trajo consigo cambios en las políticas económicas, laborales y educativas de México, lo que propició a una creciente disputa entre el Estado posrevolucionario y el capital extranjero.

\section{2. "Corresponde a la Nación el dominio directo de todos los minerales". La Revolución mexicana y la Constitución de 1917.}

Porfirio Díaz logró su reelección como presidente de México en 1910 gracias al control que mantenía sobre las instituciones y a que mandó encarcelar a su principal oponente: Francisco I. Madero. Éste había alcanzado un alto grado de popularidad durante su campaña como candidato del Partido Antireeleccionista a la presidencia; tras ser encarcelado, hizo un llamado a levantarse en armas contra Díaz; y obtuvo una vigorosa respuesta de diferentes sectores políticos y populares. La Revolución mexicana dio inició en noviembre de 1910 y si bien logró la renuncia de Díaz en 1911, su fase armada se prolongó por más de 10 años debido a factores como el asesinato de Madreo en 1913 y el sucesivo enfrentamiento de diversas facciones y caudillos por todas partes del país. Tanto la educación como la industria minera mexicana resintieron los efectos del enfrentamiento armado (Knight, 1996). El número de escuelas disminuyó drásticamente debido a la inseguridad, la falta de pago a los maestros y a las constantes tomas de las poblaciones por parte de los diferentes grupos de revolucionarios (Loyo, 2010: 154-156). La minería enfrentó también incertidumbre en la provisión de mano de obra, el suministro de insumos y el transporte de mercancías. Bernstein señala que el periodo más crítico para la industria minera tuvo lugar entre 1914 y 1916, ya que sus indicadores de producción llegaron a las cifras más bajas; pero establece también que la industria minera mexicana inició su recuperación a partir de $1917 .{ }^{6}$

La Constitución de 1917 sentó las bases legales para un proceso de transformaciones sociales, económicas y políticas. La Revolución mexicana pasó de su fase armada a la construcción de un nuevo Estado fundamentado en los nuevos postulados constitucionales. El Artículo 27 retomó la concepción de propiedad de la nación sobre los recursos del subsuelo "Corresponde a la Nación el dominio directo de todos los minerales o substancias que en vetas, mantos, masas o yacimientos, constituyan depósitos [...]; los combustibles minerales sólidos; el petróleo y todos los carburos de hidrógeno sólidos, líquidos o gaseosos". 7 Por su parte, el Artículo 123 estableció los principios de la política laboral que debía regir las relaciones entre los patrones, los trabajadores y el Estado; de tal forma que alteró los principios que habían regido la relación obrero patronal durante el porfiriato, pues "En un breve tiempo, el indiscutible derecho del capital para contratar y despedir, para operar o

\footnotetext{
6 “Miner's Problems, 1910-1917" y “The recovering of Mining, 1917-1920”, en Bernstein (1964: 95-105 y 118-123).

${ }^{7}$ Artículo 27 de la "Constitución Política de los Estados Unidos Mexicanos que reforma la de 5 de febrero de 1857”, Diario Oficial de la Federación, Lunes 5 de febrero de 1917, Tomo V, 4ª Época, Número 30, p. 150. Véase "New Taxes, New Laws and the Constitution of 1917" (Bernstein 1964: 106-117) y "Consecuencias de la Revolución en la economía minera" (Sariego et al. 1988: 54-74).
} 
clausurar cuando el propietario lo juzga conveniente, fue contrariado por el derecho de los trabajadores a su trabajo y a un salario justo" (Bernstein 1964: 115). Ambos artículos constituyeron la base legal que facultó al Estado posrevolucionario para disputar al capital extranjero el control sobre los enclaves mineros, pero estos principios se vieron obstaculizados por el poder y la influencia de las grandes trasnacionales que dominaban las industrias estratégicas: ferrocarriles, petróleo, electricidad y minería.

Los consorcios mineros trasnacionales expresaban desconfianza por el rumbo que tomaba la política laboral mexicana tras la promulgación de la Constitución de 1917, contaban con que llegarían a arreglos "amistosos" para continuar detentando el dominio sobre la industria minera como hasta entonces lo habían logrado. Diversas publicaciones la E\&MJ revelaban esta exigencia de los capitalistas estadounidenses, como lo muestra una nota de la sección "Noticias industriales desde Washington" de febrero de 1919:

Si el presidente Carranza [1917-1920] es sincero en su deseo manifiesto de un arreglo justo y amistoso con los propietarios extranjeros de fundos petroleros y minas, y si él está realmente en posición de "hacer buenas" sus promesas, dice The Evening Sun del 8 de febrero, sería una situación excelente, especialmente para México. ${ }^{8}$

En abril de 1922 D. A. Richardson publicó un análisis acerca de la nueva situación legal de la industria minera norteamericana en México derivada de la nueva política de propiedad que dictaba límites estrictos para los extranjeros en cuanto a posesión de tierras. ${ }^{9}$ En diversos momentos y foros, los empresarios mineros expresaban abiertamente su rechazo a leyes laborales mexicanas consideradas por ellos como "bolcheviques". La revista E\&MJ publicó una extensa editorial en septiembre de 1922 con el fin de analizar la política laboral mexicana durante el gobierno de Álvaro Obregón (1920-1924) y en el marco de la nueva ley del trabajo del estado de Chihuahua. El texto manifestaba una seria preocupación debido a que "por primera vez, en dos de las más grandes ciudades del estado [de Chihuahua], las banderas rojinegras fueron desplegadas a la cabeza de grandes manifestaciones. El presagio es siniestro". ${ }^{10}$ A partir de estos acontecimientos, esta editorial planteaba que el Artículo 123 y la política laboral mexicana eran promotoras de un socialismo violento y de doctrinas bolcheviques que habrían de limitar las nuevas inversiones e implicaban grandes dificultades para mantener las ya existentes.

Aunque los capitalistas mineros expresaban desconfianza ante los cambios en la legislación mexicana, en realidad consideraban a México como un espacio apto para seguir realizando negocios lucrativos durante la década de 1920. Los grandes consorcios estadounidenses emprendieron un enorme proceso expansivo por todo México y consolidaron su dominio sobre este mercado. La ASARCO, puso de manifiesto esta confianza tácita a través de sus inversiones de grandes capitales a partir de 1923 en Cerro de San Pedro y

\footnotetext{
8 "The situation in Mexican Affairs", en Engineering and Mining Journal, vol. 107, No. 7, 15 de febrero de 1919, p. 330. Mi traducción.

9 D. A. Richardson, "Mexican mining law under the new constitution of 1917", Engineering and Mining Journal, Vol. 113 no. 13, 1 de abril de 1922, pp. 525-527.

${ }^{10}$ Engineering and Mining Journal, vol. 114, No. 10, 2 de septiembre de 1922, pp. 414-416. Mi traducción.
} 
Morales (estado de San Luis Potosí); en estos casos he documentado cómo la empresa estableció la infraestructura para dotar a las comunidades mineras de servicios urbanos, educativos, de salud y recreación (Medina, 2018). Berstein (1964: 143-147) y Sariego et al. (1988) también muestran este crecimiento de las inversiones estadounidenses, así como el amplio margen de control que los consorcios extranjeros seguían manteniendo sobre las comunidades mineras. Sólo a partir de 1930, el Estado posrevolucionario logró alterar la estructura monopólica de propiedad en la industria minera, particularmente durante el sexenio del presidente Lázaro Cárdenas (1934-1940).

\section{3- "Que el Poder Público intervenga con medidas adecuadas". Una nueva relación entre el Estado y los consorcios mineros.}

Aunque la Constitución de 1917 había sentado las bases jurídicas para consolidar la soberanía nacional ante las industrias controladas por el capital extranjero; ${ }^{11}$ en la práctica el nuevo Estado tenía un margen de acción limitado por diversidad de factores internos y externos (Matute, 1980). Desde comienzos de la década de 1920, el gobierno federal implementó estrategias que tenían como propósito: a) fortalecer su poder y su presencia en todo el país ante los gobiernos locales, b) someter a caudillos y facciones revolucionarias disidentes, c) contrarrestar la oposición de poderes facticos como la Iglesia, empresarios y latifundistas, y d) lograr el reconocimiento de los capitalistas extranjeros y su obediencia a las nuevas leyes e instituciones. A lo largo de este proceso; la creación de un sistema educativo nacional, el fortalecimiento y control de obreros y campesinos, así como el desarrollo de un amplio proyecto nacionalista tuvieron especial importancia para enfrentar a las empresas trasnacionales que controlaban las industrias petrolera, minera, eléctrica y ferrocarrilera.

Durante la década de 1930, la estatización de industrias estratégicas fue una medida fundamental en el proceso de fortalecimiento del Estado posrevolucionario ante el capital extranjero. El gobierno de Lázaro Cárdenas (1934-1940) creó la Comisión Federal de Electricidad (1937) ${ }^{12}$ y expropió las industrias ferrocarrilera $(1937)^{13}$ y petrolera $(1938)^{14}$ tras sendos procesos de tensiones durante los cuales los consorcios extranjeros se negaron sistemáticamente a acatar las disposiciones de las nuevas leyes e instituciones, principalmente en materia laboral. El decreto de expropiación de la industria petrolera declaraba que "Es urgente que el Poder Público intervenga con medidas adecuadas" ante la negativa de las empresas petroleras a acatar el fallo de la Suprema Corte de Justicia de la Nación (SCJN) que las obligaba a establecer nuevas condiciones laborales y ante el inminente paro de esta industria. Si bien el régimen cardenista no expropió la industria minera; sí expidió leyes que

\footnotetext{
${ }^{11}$ El Artículo 27 otorgó al Estado la facultad de expropiar los bienes en manos del capital privado por causas de interés público.

${ }^{12}$ LEY que crea la Comisión Federal de Electricidad. Diario Oficial de la Federación, martes 24 de agosto de 1937, Tomo CIII, Número 47, pp. 1-3., pp. 3-6.

13 ACUERDO que expropia, por causa de utilidad pública, los bienes pertenecientes a la empresa Ferrocarriles Nacionales de México, S. A. Diario Oficial de la Federación, Acuerdo publicado el jueves 24 de junio de 1937, Tomo CII, Número 38, pp. 1-3.

14 DECRETO que expropia a favor del patrimonio de la Nación, los bienes muebles e inmuebles pertenecientes a las compañías petroleras que se negaron a acatar el laudo de 18 de diciembre de 1937 del Grupo Número 7 de la Junta Federal de Conciliación y Arbitraje. Diario Oficial de la Federación, Decreto publicado el sábado 19 de marzo de 1938, Tomo CVII, Número 17, pp. 1-2.
} 
limitaron el tamaño de las concesiones e incrementaron las obligaciones tributarias, impulsó la formación de cooperativas de producción minera y del sindicato nacional, y creó la Comisión de Fomento Minero (Sariego et al., 1988: 151-160).

Desde 1920, el gobierno federal se había propuesto reconstruir la economía nacional y había emprendido un proceso centralizador cuya finalidad era consolidar su poder frente a los otros niveles de gobierno y ante los diversos poderes al interior y exterior del país. ${ }^{15}$ Estos gobiernos buscaron su fortalecimiento mediante la centralización de numerosos aspectos de la administración pública y la recaudación fiscal; con este fin impulsaron una serie de reformas legislativas que ampliaban su jurisdicción y facultades legales. ${ }^{16}$ La educación fue parte fundamental de este proyecto centralizador.

El gobierno federal promovió una reforma constitucional que le permitió crear la Secretaría de Educación Pública (SEP) en 1921 con amplias facultades para fundar escuelas primarias en todo el territorio nacional. ${ }^{17} \mathrm{La}$ SEP emprendió un proyecto educativo y cultural de gran escala mediante el establecimiento de escuelas primarias tanto en lugares donde no existían como en otros donde ya había planteles establecidos por los gobiernos locales; con el tiempo, las primarias federales tendieron a suplir y desplazar a los sistemas educativos de los estados y municipios. ${ }^{18}$ Según Loyo, en lo relativo a la educación, "la etapa centralizadora tuvo su mayor auge en los años veinte y treinta y fue paralela a la federalización [entendida como centralización] que se realizaba en otros ámbitos de la vida nacional" (Loyo 1999: 50).

A través de la labor de los maestros, la SEP se proponía inculcar un nuevo sentido de ciudadanía y modernidad, así como movilizar a campesinos y obreros para crear las bases sociales que el régimen requería. Las políticas educativas prescritas por la SEP se revestían de un halo de sentido patriótico fundado en la promoción de héroes nacionales; promovían principios de higiene, salud, trabajo y disciplina; y tenían la finalidad de generar mujeres y hombres productivos, laboriosos y aptos para el trabajo en la industria, el comercio y los servicios que el Estado pretendía impulsar. Vaughan (2000: 49-84) analiza las políticas culturales de la SEP y su recepción en el medio rural y muestra las transformaciones sociales que el proyecto educativo se proponía implementar más allá de los espacios escolares: educación de adultos, mayor participación social y económica de las mujeres, mejoramiento de las medidas de higiene y alimentación, adopción de la medicina moderna, modernización de los espacios domésticos y públicos, organización de cooperativas y pequeñas industrias, combate al alcoholismo y promoción de formas más sanas de recreación. Pero los maestros enfrentaron constantemente el rechazo social hacia las políticas escolares dispuestas por la SEP, ya fuera debido a que éstas eran incompatibles con las tradiciones locales (como el principio de laicidad) o a que las comunidades no contaban con los medios e infraestructura para llevarlas a la práctica (como en el caso de la disponibilidad de agua potable) (Vaughan, 2000 y Medina, 2011).

\footnotetext{
${ }^{15}$ Diversos historiadores estudian la formación y consolidación del poder federal posrevolucionario: Meyer, Krauze y Reyes (1996), Krauze, Meyer y Reyes (1997) y Córdova (1996) analizan el periodo que corresponde a las reformas referidas 1920-1934.

16 Acerca de este conjunto de reformas véase el apartado "El proceso de federalización" en Medina (2015: 177-180).

17 Diario Oficial de la Federación, DECRETO estableciendo una Secretaría de Estado que se denominará Secretaría de Educación Pública, publicado el lunes 3 de octubre de 1921.

${ }^{18}$ En 1925 el sistema federal de escuelas primarias alcanzó un número de 2,443 escuelas (21\% del total) que atendían a 267, 900 alumnos; para 1936 el número de escuelas era de 11,445 (59\% del total) con un número de alumnos de 969,341. INEGI, Anuario Estadístico de los Estados Unidos Mexicanos, (1930: 191 y 195) y (1938: 92, 100-101).
} 
La agenda de transformaciones socioculturales de la SEP coincidía con las políticas de los empresarios mineros en aspectos como: generar espacios públicos y domésticos modernos e higiénicos, generar hombres y mujeres más sanas, laboriosas y disciplinadas a través de la educación, los hábitos de higiene, la medicina moderna, el combate al alcoholismo y el fomento de los deportes. Tanto la SEP como las empresas mineras esperaban que los deportes modernos contribuyeran a desterrar de los hombres prácticas perniciosas como los juegos de azar, el alcoholismo y la recurrencia al sexo servicio, "los deportes de grupo (basquetbol y béisbol) pasaron a ser la panacea contra la degeneración masculina” (Vaughan 2000:76). El gerente de la planta fundidora ASARCO de San Luis Potosí ofreció realizar mejoras a la escuela que financiaba a condición de que las autoridades educativas gestionaran la clausura de los expendios de bebidas alcohólicas en la localidad de Morales; por ello el director de educación federal hizo esta petición a la autoridad municipal en abril de 1936:

La dirección a mi cargo [...] suplica a usted se digne ordenar sean clausuradas las tabernas y cantinas existentes en la Fracción de Morales, ya que positivamente están causando graves daños al funcionamiento de la escuela pues a simple vista, se advierte que la condición de los niños que concurren a la misma es muy poco satisfactoria porque sus padres dilapidan en dichos Centros de vicio lo que debieran dedicar al sostenimiento de sus familias. ${ }^{19}$

No obstante estas coincidencias, los capitalistas extranjeros y el Estado mexicano lucharon por hacer prevalecer sus respectivos proyectos para el desarrollo de la actividad minera. En 1934, la intervención del gobierno federal en las escuelas financiadas por los patrones agudizó el enfrentamiento entre ambas partes.

\section{4. "Los forjadores de hombres": Las comunidades mineras y las disputas por el control de las escuelas.}

Tanto el Estado posrevolucionario como los consorcios mineros se adjudicaban el derecho de ser "los forjadores de los hombres", es decir, de imprimir en los obreros y sus familias un modelo ideológico afín a sus intereses. Coincido con Sariego et al., (1988) en que la historia de la minería mexicana durante el siglo $\mathrm{XX}$ se puede explicar como la confrontación de dos proyectos antagónicos: uno del capital extranjero (de enclave), y otro del Estado mexicano en alianza con los trabajadores (nacionalista). El control de las escuelas y los espacios públicos fue un campo de disputas surgido en el marco de esta confrontación, estaba influido por tensiones en torno de: la soberanía nacional y la posesión de la tierra, las políticas que habrían de regir la actividad minera y la orientación ideológica de las escuelas. Sariego et al. (1988) identifican tres periodos en la historia de la minería mexicana del siglo XX: $1^{\circ}$ el desarrollo y crisis del proyecto extranjero de enclave (1890-1929), $2^{\circ}$ la intervención del Estado y la defensa del proyecto de enclave (1930-1950), y $3^{\circ}$ la

\footnotetext{
${ }^{19}$ Carta de Jacinto E. Téllez, director de educación federal al presidente municipal de San Luis Potosí, "Asunto: Pide clausura de establecimientos bebidas embriagantes, ubicados en Fracc. Morales", 2 de abril de 1936. AHSEP, EA123SLP C68, E14, ff. 6 y 7.
} 
"mexicanización de la minería" a partir de 1950. En este apartado abordo el segundo periodo, muestro algunas formas concretas en que acontecieron las disputas y tomo casos particulares para ilustrar cómo el Estado mexicano combatió con relativo éxito el proyecto de enclave durante la década de 1930, en tanto que los capitalistas extranjeros aprovecharon la coyuntura de la Segunda Guerra Mundial para emprender una lucha por la defensa de su proyecto.

Además de dictar los principios fundamentales que debían regir las relaciones de trabajo, el Artículo 123 dispuso en su fracción XII que era obligación de los patrones establecer y financiar escuelas para los hijos de sus trabajadores cuando los centros de trabajo estaban ubicados fuera de poblaciones establecidas o cuando empleaban "un número de trabajadores mayor de cien". ${ }^{20}$ La Constitución de 1917 otorgó a los gobiernos de los estados la función de velar por el cumplimiento de esa disposición. Pero en 1932 el gobierno federal propuso una reforma constitucional para obtener la jurisdicción sobre las entonces llamadas "escuelas de los patrones"; argumentaba que era necesario "un cambio de las autoridades encargadas de cuidar el cumplimiento de tales deberes", debido a que los gobiernos de los estados no hacían cumplir ese precepto. ${ }^{21}$ En enero de 1934, la federación obtuvo la jurisdicción sobre las "escuelas de los patrones". ${ }^{22}$ La SEP quedó establecida como la autoridad que tomaría el control de los centros educativos ya existentes y obligaría a los patrones omisos a financiar más de tres mil nuevos planteles; con este fin, dio un vigoroso apoyo a la fundación de las nuevas escuelas federales “del Artículo 123" (Medina, 2012: 98-122).

No obstante, la SEP enfrentó una enérgica oposición de los patrones a la fundación de nuevas escuelas y a la federalización de las ya existentes; tuvo que afrontar también la oposición de gobiernos y legislaturas estatales inconformes con "los excesos de la Secretaría de Educación" (Medina, 2015: 181-182). Muchas escuelas propuestas por los inspectores federales no llegaron a fundarse, mientras que otras tuvieron una permanencia efímera. ${ }^{23}$ Tanto los patrones nacionales como los consorcios extranjeros limitaron las acciones de esta secretaría a través de la abierta rebeldía o, con más frecuencia y éxito, por la vía de las disputas jurídicas. ${ }^{24}$ La gran mayoría de los consorcios extranjeros financiaban escuelas para los hijos de sus trabajadores aun antes de que la SEP obtuviera la jurisdicción sobre las "escuelas de los patrones". A pesar de la vigencia de esta política empresarial, la SEP enfrentó una oposición constante y sistemática a la fundación, financiamiento y ampliación de las escuelas industriales, principalmente de la minería.

\footnotetext{
${ }^{20}$ Fracción XII del artículo 123 según el texto constitucional de 1917. Diario Oficial de la Federación, Constitución Política de los Estados Unidos Mexicanos, que Reforma la de 5 de Febrero de 1857, publicada el lunes 5 de febrero de 1917, Tomo V, Número 30.

21 "Exposición de motivos". Iniciativa para diversas reformas encaminadas a la federalización de las escuelas Artículo 123, presentada por el presidente Abelardo L. Rodríguez a la Cámara de Diputados. Diario de los Debates de la Cámara de Diputados del Congreso de los Estados Unidos Mexicanos, XXXV Legislatura, sesión del 19 de 0ctubre de 1932.

${ }^{22}$ Reformas publicadas el 18 y 20 de enero de 1934 en el Diario Oficial de la Federación.

${ }^{23} \mathrm{Si}$ bien disponemos de pocos estudios acerca de estos procesos, los trabajos existentes muestran que las autoridades educativas federales enfrentaron serias dificultades para la fundación y permanencia de estas escuelas. Véase Loyo (1990: 316-333); en el estado de Tlaxcala, Rockwell (2007: 289-291); en el estado de Chiapas, Lewis (2010).

${ }^{24}$ En Medina (2015) he analizado la implementación de los alegatos jurídicos como la estrategia patronal más exitosa para combatir las disposiciones de la SEP en cuanto a obligaciones patronales en materia de educación. Véase también Loyo (1990: 317-324) y Greaves (2008: 200-203).
} 
En enero de 1934, la industria minera trató de evitar la pérdida del control que mantenía sobre sus escuelas y para ello echó mano de los vínculos que tenía con autoridades locales. Los gobiernos de algunos estados intentaron establecer como ilegal la intervención de la SEP en las "escuelas de los patrones" para convertirlas en escuelas federales llamadas Artículo 123 a partir de entonces (Medina, 2015). Las legislaturas de los estados de Querétaro y Coahuila encabezaron un movimiento de oposición que declaraba ilegal la federalización de las "escuelas de los patrones": "Creemos jurídico afirmar que [...], el texto de la reforma no favorece el intento de la Secretaría de Educación Pública, al tratar de intervenir en las Escuelas que actualmente controla el Estado [es decir, los gobiernos estatales]". ${ }^{25}$ Pero el Congreso de la Unión demostró la legalidad de las nuevas disposiciones; de tal forma que los intentos de revertir la reforma y de detener el proceso de federalización por la vía legislativa quedaron conjurados durante los primeros meses de 1934. Aunque las inconformidades aludían a la jurisdicción sobre las escuelas, en el fondo de estas controversias yacían las protestas del poder patronal. La intervención del gobierno federal alteraba los convenios consuetudinarios locales para que los patrones cumplieran a voluntad el mandato de sostener escuelas y mantuvieran un amplio control sobre éstas.

Otra de las primeras formas de responder a la federalización de las escuelas mineras fue la abierta negativa a acatar los mandatos de la SEP. Un buen ejemplo de ello es la federalización de la escuela de la Negociación Minera Santa María de la Paz y Anexas (subsidiaria de la ASARCO) en el estado de San Luis Potosí en enero de 1934. Esta empresa se negó rotundamente a permitir que la SEP tomara el control de su escuela; mantuvo esa postura hasta marzo de 1935, cuando aceptó financiar la escuela Artículo 123 de Villa de la Paz, y solicitó a cambio que la autoridad educativa le condonara las numerosas multas de $\$ 100$ acumuladas durante más de un año de desacato (Medina, 2012:105, 120-121). El plantel de Villa de la Paz comenzó a funcionar como escuela Artículo 123 en abril de 1935 con una población escolar de 580 alumnos, atendidos por seis maestros y un director. ${ }^{26}$

El poder patronal recurrió a la promoción de amparos, ante la poca eficacia de la abierta negativa a financiar las escuelas federalizadas; a través de esta estrategia mantuvo una vigorosa y prolongada resistencia a las obligaciones impuestas por la SEP. En 1935, la empresa minera Compañía Real del Monte y Pachuca, en el estado de Hidalgo, promovió dos amparos contra la obligación de financiar escuelas Artículo 123 en Pachuca (capital del estado) y el Real del Monte. En 1936, la SCJN sentenció que la obligación de sostener escuelas Artículo 123 "no puede existir cuando la instalación de aquéllas se efectúe en centros de población, ya existentes con anterioridad a su funcionamiento". ${ }^{27}$ Pero la Corte también estableció que la empresa debía financiar ambas escuelas aun cuando se encontraban en zonas urbanas, ya que el origen de éstas era la actividad económica desarrollada por la compañía. A pesar de esta sentencia, la Compañía Real del Monte y Pachuca continuó negándose varios años a sostener las escuelas y recurrió a nuevos argumentos jurídicos para ello.

\footnotetext{
${ }^{25}$ Resolución del Congreso de Coahuila dirigida a la Cámara de Diputados. Diario de los Debates de la Cámara de Diputados del Congreso de los Estados Unidos Mexicanos, XXXV Legislatura, Año II, Período Ordinario, Tomo II, Número de Diario 37, México, D. F. miércoles 14 de febrero de 1934.

${ }^{26}$ Expediente de la escuela Artículo 123 de Villa de la Paz. AHSEP, DGEPET, EA123SLP E70 L1 pp. 1-72.

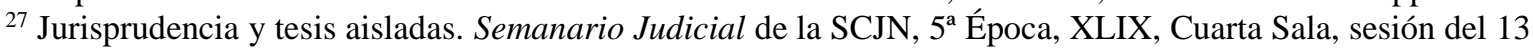
de agosto de 1936, p. 410.
} 
La SCJN también estableció en este fallo que sólo era obligación de los patrones brindar educación a los hijos de sus trabajadores "la obligación de la empresa debe estimarse subsistente respecto al mantenimiento de la escuela que la misma haya establecido; pero sin que se la considere obligada a proporcionar ese servicio a hijos de personas que no sean sus trabajadores". ${ }^{28}$ Pero la SEP debatió legalmente este criterio argumentando que un asentamiento humano viable no podía componerse sólo de trabajadores mineros, pues las familias establecidas en estos centros de población requerían de personas dedicadas al comercio y los servicios para proveerse de todo lo necesario para la subsistencia. Durante años, esta secretaría insistió en la obligación patronal de proveer educación a los hijos de quienes, con su trabajo, hacían posible la vida en los centros mineros: comerciantes de todo tipo, peluqueros, herreros, albañiles, panaderos, carpinteros, etc. Los patrones y la SEP emprendieron largas querellas legales y administrativas a causa de la asistencia de hijos de no trabajadores de las empresas a las escuelas Artículo 123.

Las empresas mineras y la SEP se diputaron constantemente el control de los maestros. En 1936 el presidente Cárdenas promulgó un decreto por el cual los maestros de las escuelas Artículo 123 pasaban a ser considerados como empleados federales. ${ }^{29}$ Pero esta disposición dio a los patrones argumentos jurídicos para deslindarse de responsabilidades laborales. En 1937, Cárdenas emitió un nuevo decreto según el cual estos maestros adquirían la categoría de "empleados de planta" de las empresas en cuyas escuelas trabajan, con todos los derechos y obligaciones legales. ${ }^{30}$ Los patrones respondieron a este decreto con nuevos alegatos jurídicos, ya que reclamaban el derecho de mantener el control sobre los maestros como sus "empleados de planta". Las pugnas legales impusieron algunas limitaciones a la SEP en su jurisdicción sobre los maestros durante los años siguientes.

En 1938, la SEP impuso la obligación de aumentar los sueldos de directores y maestros a una compañía minera que financiaba tres escuelas en el estado de Chihuahua. La empresa El Potosí Mining Company (perteneciente a la ASARCO) promovió y obtuvo un amparo en contra de tales disposiciones. ${ }^{31}$ La SEP impugnó esa sentencia ante la SCJN pero el fallo de la Corte limitó las facultades de la Secretaría para decidir los salarios que debían ser pagados a directores y maestros basada en el decreto de Cárdenas de 1937: "Las empresas que crean escuelas 'Artículo 123' no tienen obligación de aumentar el sueldo a los profesores. [La SEP] se ha excedido en el ejercicio de sus facultades, únicamente reducidas a dirigir técnica y administrativamente la designación y las funciones de los expresados maestros". ${ }^{32}$

\footnotetext{
${ }^{28}$ Jurisprudencia y tesis aisladas. Semanario Judicial de la SCJN, 5ª́poca, XLIX, Cuarta Sala, sesión del 13 de agosto de 1936, p. 410.

${ }^{29}$ Decreto por el cual se consideran como empleados federales a los maestros de las escuelas tipo Artículo 123, Diario Oficial de la Federación, Tomo XCV, Número 46, Sección Primera, p. 6, Jueves 23 de abril de 1936.

30 "Decreto que reforma el de 13 de abril de 1936, por el cual se consideran como empleados federales a los maestros de las escuelas tipo Artículo 123". Diario Oficial de la Federación, Número14, Tomo CV, 16 de noviembre de 1937.

31 Juicio de amparo promovido en el Juzgado Primero de Distrito de Chihuahua, Chihuahua. Contra la resolución de la SEP contenida en el oficio número 14700, expediente IV.130.01 (721.4), 9 de marzo de 1938, por la que se obliga a la compañía El Potosí Mining Company aumentar el sueldo de directores y maestros de las escuelas Artículo 123 que la empresa sostenía en Francisco Portillo, municipio de Aquiles Serdán, y en San Guillermo y Robinson, municipio de Chihuahua, a partir de enero de 1938.

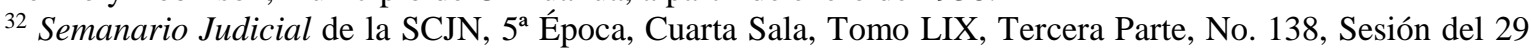
de marzo de 1939, pp. 473-474.
} 
También en 1938, la fundición de la ASARCO en Ávalos (estado de Chihuahua) promovió y obtuvo otro amparo que limitaba las facultades de la SEP para otorgar a los maestros permisos para ausentarse de sus labores con goce de sueldo. Aunque la SEP impugnó esta sentencia, la SCJN determinó que la categoría de "trabajadores de planta" de los maestros limitaba a la secretaría para aplicar sus propias disposiciones administrativas. ${ }^{33}$

Las empresas mineras debatieron legalmente muchas otras disposiciones de la SEP al respecto de las escuelas que financiaban: aumento del número de maestros, construcción de nuevas aulas, dotación de materiales escolares, mejoras y ampliaciones a los edificios, entre otras. Tanto el Estado mexicano como el capital extranjero recurrieron a estas disputas legales cómo estrategia para hacer prevalecer sus respectivos proyectos para la minería, lo que constituyó un periodo particularmente conflictivo. ${ }^{34}$

A pesar de que las empresas mineras articularon una sistemática oposición a ceder el control de sus escuelas a la SEP, esta secretaría logró notables avances en el establecimiento de su autoridad en estos centros educativos y en la aplicación de sus políticas y programas. En la mayoría de los casos, las empresas mineras sostuvieron grandes centros escolares federalizados y caracterizados por contar con instalaciones, mobiliario y materiales que superaban por mucho las condiciones en que trabajaban las escuelas financiadas por la SEP. Sin embargo, el gobierno de Lázaro Cárdenas también se vio en la necesidad de moderar sus políticas ante la presión nacional e internacional posterior a la expropiación del petróleo (1938), circunstancias que lo condujeron a reemplazar a secretarios de estado de corte radical y a impulsar a un sucesor presidencial más afín a las fuerzas conservadoras. ${ }^{35}$ Los gobiernos que sucedieron al cardenismo impulsaron políticas que dieron un paulatino viraje a la relación con los empresarios y los sindicatos, así como al proyecto de la "educación socialista" implementado por Cárdenas.

Desde la coyuntura de la Segunda Guerra Mundial, el presidente Manuel Ávila Camacho (1940-1946) hizo un llamamiento a la "unidad nacional", lo que significaba evitar las confrontaciones internas, como las huelgas. El gobierno y los empresarios mineros pidieron al sindicato nacional una actitud de "cooperación" en materia de exigencias laborales y aumentos de salarios (Bernstein, 1964: 225-226); en tanto que el líder de la confederación obrera nacional llamó a los obreros al sacrificio "renunciando al sagrado derecho de la huelga". ${ }^{36}$ Diferentes autores coinciden en señalar los sexenios de Manuel Ávila Camacho y Miguel Alemán Valdés (1946-1952) como un periodo de enfrentamiento entre el sindicato y el bloque de las empresas mineras, éstas aprovecharon la coyuntura de la guerra y las políticas gubernamentales de apoyo al sector privado para recuperar antiguos privilegios (Gaitán, 1987 y Besserer et al., 1983). Estos gobiernos se propusieron debilitar al sector obrero como

${ }^{33}$ Semanario Judicial de la SCJN, 5a Época, Tomo LIX, Cuarta Sala, sesión del 20 de septiembre de 1939, p. $481-483$

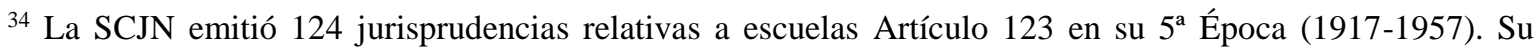
número de 115 entre 1934 y 1945 revela el periodo más conflictivo en estas relaciones; en tanto que entre 1946 y 1957 se emitieron sólo 9. Semanario Judicial de la SCJN, 5ª Época, 1 de junio de 1917-30 de junio de 1957.

${ }^{35}$ En Cardenismo: Juggernaut or Jalopy? Knight ha planteado profundas interrogantes acerca del significado del régimen cardenista: ¿qué tan radical, democrático, poderoso y efectivo para llevar a cabo sus políticas fue realmente el Cardenismo? Knight (1994). Véase también Gilly (1997).

${ }^{36}$ Declaración de Fidel Velázquez, líder de la Confederación de Trabajadores de México (CTM), 26 de mayo de 1942. El Heraldo de San Luis, 27 de mayo de 1942, p. 1 
estrategia central para lograr su control. El llamado a la "unidad nacional" ante la contingencia de la guerra y la participación de México en el conflicto a partir de 1942 sirvieron a este propósito (Besserer et al., 1983: 39 y 40). Por su parte, el gobierno de Miguel Alemán Valdés intervino en la vida interna de los sindicatos con el fin de debilitar el movimiento obrero mexicano; y declaró inexistentes o ilegales la mayoría de las huelgas. Ambos gobiernos se caracterizaron por otorgar fallos a favor de las grandes compañías mineras; mientras que las instituciones encargadas de velar por los trabajadores se convirtieron en aliadas de los patrones: "Los mineros deben ser menos exigentes con las compañías [declaración del Secretario del Trabajo Lic. Manuel Ramírez Vázquez]"37.

Las circunstancias antes descritas se reflejaron en las comunidades mineras, sus escuelas y espacios públicos. Al comienzo de la década de 1940, el gobierno federal había logrado hacerse del control de las escuelas establecidas y financiadas por las empresas mineras, había instaurado algunas prácticas escolares, transformaciones en las comunidades y rituales cívicos orientados a forjar su modelo de ciudadano. A través de las escuelas, la SEP había impulsado con éxito algunos cambios en las formas de vida tanto en espacios públicos como privados: prácticas de higiene en casa, alimentación más saludable, construcción de espacios públicos (teatros, campos deportivos, jardines, talleres y cocinas, entre otros), práctica de deportes, uso de medicina moderna, etc. Pero el notable éxito de las políticas educativas en estas comunidades se debía en gran parte a la dotación de servicios urbanos y de salud provistos por las compañías mineras, ya que el Estado no había creado agencias gubernamentales que las proveyeran a centros de población más o menos lejanos. El control y la oferta de la mayoría de los servicios públicos estaban en manos de las empresas, de tal forma que las comunidades mineras se encontraban a merced de la buena voluntad de las compañías para proveérselos.

El pueblo minero de Cerro de San Pedro es un buen ejemplo de las políticas gubernamentales antes descritas, de las disputas entre la SEP y los consorcios mineros, y de su pernicioso control sobre los servicios públicos. En este caso, la SEP y la sección 7 del sindicato minero mantuvieron tensas relaciones con la ASARCO; ya que, desde 1935, la compañía era reticente a cumplir con su obligación de financiar la escuela Artículo 123 "Centenario" y a incrementar los gastos que ya realizaba para este propósito. La empresa promovió un amparo en 1935, pero la SCJN se lo negó definitivamente en 1939 y la sentenció a cumplir con las obligaciones que la SEP le imponía. ${ }^{38}$ Aunque la ASARCO se vio instada a incrementar sus gastos en la escuela "Centenario", en realidad cumplió en lo mínimo posible las sentencias pues siguió funcionando en un edificio propiedad del gobierno municipal. Aunque este conflicto alcanzó un punto de equilibrio durante los primeros años de la década de 1940, las tensiones se reavivaron en 1945. ${ }^{39}$ Tras 10 años de alegatos y juicios, la compañía se vio obligada a proveer de casa a los maestros y aumentar su número, construir más aulas, hacer mejoras al edificio escolar y suministrar un mayor número de materiales a la

${ }^{37}$ El Heraldo de San Luis, 15 de febrero de 1948, p. 1

38 Acuerdo de la $4^{\text {a }}$ Sala de la SCJN, México, D. F., 26 de julio de 1939. AHSEP, DGEPET, EA123SLP, C70, E7, pp. 80-107.

${ }^{39}$ Los problemas no estaban resueltos de fondo. La ASARCO no contaba con un edificio propio para su escuela Artículo 123. El sindicato y las autoridades educativas insistían en que la empresa construyera un edificio escolar tal como lo había hecho en otros centros mineros. AHSEP, DGEPET, EA123SLP, C70, E7, pp. 80-107. 
escuela. No obstante, la ASARCO eludió la obligación de construir un edificio escolar mediante el arrendamiento del edificio que ya ocupaba, pues tan sólo requería de un par de años más para dar por finalizado el periodo previsto para la extracción de los recursos mineros de Cerro de San Pedro. ${ }^{40}$

Cuando las reservas minerales explotables de este pueblo estaban a punto de agotarse, la empresa echó mano de estrategias fraudulentas para retirarse del lugar sin responsabilidades con los trabajadores, además envió con ello un mensaje de intimidación para otras unidades mineras y secciones sindicales que se encontraban en luchas y negociaciones por mejorar sus condiciones laborales y salariales. La ASARCO cerró sus operaciones en Cerro de San Pedro "como resultado de una serie de incendios subterráneos que ardieron fuera de control, por lo cual el gobierno mexicano otorgó el permiso para su cierre por causas de fuerza mayor". ${ }^{41}$ Inexplicablemente la empresa minera mantuvo en secreto el incendio de 1948 y permitió que se propagara durante varios días; mientras que el gobierno de Miguel Alemán autorizó el cierre de operaciones sin atender a las denuncias de los trabajadores. ${ }^{42}$ Tras el abrupto cierre de la ASARCO, la escuela Artículo 123 fue clausurada en 1949 y en su lugar siguió funcionando la escuela rural federal Benito Juárez.

Con el cierre de la actividad industrial, Cerro de San Pedro perdió de inmediato los servicios de atención médica, provisión gratuita de medicamentos, teléfono, taxis, camiones cada hora a la capital del estado, entre otros. El gobierno municipal no contaba con los recursos financieros para mantener en funcionamiento los servicios de agua potable y electricidad que dejó de proveer la empresa minera, debido a ello las infraestructuras eléctrica e hidráulica se deterioraron y se perdieron al cabo de una década. Estas circunstancias generaron una rápida disminución demográfica, el número de habitantes del lugar pasó de alrededor de dos mil en 1948 a poco más de 300 en el lapso de una década; los censos de población han registrado sólo una centena de habitantes a partir de 1970. La disminución demográfica generó también el decremento del número de alumnos en la escuela federal Benito Juárez y el consecuente cierre de la misma en $1963 .{ }^{43}$

\section{5. “El interés general de la Nación”. La mexicanización de la minería.}

La etapa que Sariego et al. (1988) designan como "mexicanización de la minería" se desarrolló a partir de 1950, principalmente durante los gobiernos de Adolfo Ruiz Cortines (1952-1958) y Adolfo López Mateos (1958-1964), a través de tres elementos fundamentales: a) la creciente participación de empresas paraestatales, b) la presencia del Estado en las comunidades mineras y c) la participación de capital mexicano. Apenas llegado al poder, López Mateos creo la Secretaría del Patrimonio Nacional cuyo titular estableció a inicios de 1959 los nuevos criterios que regirían la política minera:

\footnotetext{
${ }^{40}$ La compañía aceptó pagar \$50.00 mensuales en el entendido de que el edificio sería ocupado por la escuela Artículo 123 y la nueva escuela federal Benito Juárez, pero ambas escuelas trabajaron como una sola. Contrato de arrendamiento celebrado por el ayuntamiento de Cerro de San Pedro y la CMM, 14 de abril de 1945. AHSEP, DGEPET, EA123SLP, C70, E7, pp. 94-95.

${ }^{41}$ Hoffman (1954: 27). Mi traducción.

42 AGN, MAV, Vol. C 302, Exp. 432/126. Memorándum del secretario general del SITMMSRM, Agustín Guzmán V., al presidente Miguel Alemán Valdés, México, D. F., 20 de mayo de 1948.

${ }^{43}$ En Medina (2008 y 2018) he analizado exhaustivamente este caso.
} 
Conciliar el interés particular del explotador y el interés general de la Nación. [...] Orientar las actividades mineras en el sentido más conveniente para la colectividad y haga posible impedir la explotación de los recursos patrimoniales de la Nación de forma inconveniente o fuera del control del Estado. [...] Que el ritmo e intensidad de la explotación se ajuste no al capricho circunstancial de la empresa explotadora, sino a la conveniencia superior definida de la colectividad (Sariego et al., 1988: 251).

El Estado mexicano comenzó a participar en esta industria mediante el establecimiento de empresas mineras y promulgó leyes que obligaban a toda la industria de este ramo a contar con, por lo menos, un $51 \%$ de capital mexicano.

En lo relativo a las comunidades mineras, el Estado intervino en ellas propiciando condiciones para diversificar el mercado ocupacional y participando en la construcción de los espacios públicos mediante la llegada de agencias gubernamentales federales y estatales responsables de la dotación de servicios y equipamientos colectivos: servicios de salud, seguridad social, pensiones, desarrollo urbano, agua potable, drenaje y saneamiento, dotación de viviendas, educación, promoción del deporte y recreación, electricidad, teléfono, abasto de suministros domésticos (alimentos, ropa y enseres), entre otros. Mediante la presencia de estas agencias gubernamentales, el Estado se propuso desplazar a las empresas mineras en su papel de benefactoras y controlar aspectos específicos de la vida pública.

Pero el gobierno federal se proponía además establecer su control sobre el movimiento obrero minero y continuar favoreciendo a los empresarios ante las demandas articuladas desde el sindicato nacional. Los constantes fallos de las autoridades en favor de las empresas y las precarias condiciones salariales y laborales de los trabajadores mineros generaron movimientos obreros en contra de las políticas del gobierno. A mediados de 1950 en el estado de Coahuila, la sección 14 de Nueva Rosita entró en conflicto con el gobierno federal, ya que éste intervino para designar un secretario general dispuesto a colaborar con los intereses gubernamentales. En enero de 1951, esta sección del sindicato nacional se movilizó en una marcha hasta la Ciudad de México en demanda de: la deposición del secretario electo ilegítimamente, respeto al contrato colectivo de trabajo, reinstalación de los trabajadores cesados, reapertura de la cooperativa de consumo y la clínica, pago de salarios caídos y recursos retenidos por la empresa ASARCO. La citada marcha fue conocida como la Caravana del Hambre, recorrió casi 1600 kilómetros en camiones y otros largos tramos a pie, llegó a la ciudad de México el 9 de marzo de 1951 y contó con una amplia cobertura de los medios de comunicación. A pesar de este esfuerzo las secciones sindicales perdieron fuerza frente a un sindicato nacional aliado al poder, el gobierno negoció arreglos que en poco favorecieron a los trabajadores y la ASARCO fortaleció su posición frente a al sector obrero. Muchos trabajadores mineros y sus familias emigraron de Nueva Rosita a consecuencia del fracaso de las negociaciones y los arreglos desfavorables para ellos. (Sariego, 1982 y Sariego et al., 1988: 279).

El proceso de mexicanización de la minería tuvo un éxito relativo, ya que los capitalistas extranjeros encontraron la manera de continuar detentando el control de los consorcios mineros a pesar de la obligación de contar con un 51\% de capital mexicano. Pero 
un amplio sector de los trabajadores y las comunidades mineras sí consideraron importante la mexicanización de la minería y le otorgaron un sentido de pertenencia que llegó hasta los espacios escolares. La escuela "Asarco" de Morales, ubicada a 5 kilómetros de la capital de San Luis Potosí, cambio su nombre a escuela "Industrial Minera México" en 1974. ${ }^{44}$ Esta escuela llegó a tener una matrícula máxima de 892 alumnos distribuidos en 15 grupos en 1962 y continuó trabajando hasta 2010, año en que fue cerrada la planta fundidora de Morales (Medina 2018).

La intervención del estado en las comunidades acrecentó las posibilidades de que los asentamientos fueran capaces de subsistir a pesar del cierre de las actividades mineras industriales. El pueblo de Santa Rosalía, en el estado de Baja California Sur, se asentó a partir de las actividades de extracción de cobre de la empresa francesa El Boleo S. A. hasta 1954. El apoyo de las instancias gubernamentales permitieron que la explotación minera continuara hasta 1972, mientras que la diversificación de actividades laborales favoreció la permanencia y prosperidad del lugar hasta el presente (Romero, 1991).

\section{Algunas consideraciones finales.}

Aunque la SEP logró tomar el control de las escuelas financiadas por los patrones, estuvo lejos de cumplir la meta planteada en la iniciativa de ley que las federalizó: fundar tres mil nuevos centros educativos. En 1927 había 1,888 escuelas "de los patrones" y el mayor número de planteles Artículo 123 fue de 2,069 en 1934. Entre 1939 y 1941 el número de escuelas Artículo 123 se redujo de 1185 a 699; el 90\% de las clausuras correspondía a escuelas de haciendas agropecuarias. ${ }^{45}$ Alrededor de 500 escuelas pertenecientes a la industria permanecieron en funcionamiento durante décadas como grandes centros escolares de buen prestigio social y alta demanda de matrícula, algunas de ellas continúan trabajando hasta el presente (Medina, 2018). Sin embargo, el éxito de este proyecto del Constituyente de 1917 ha sido muy relativo. Las industrias paraestatales eléctrica, ferrocarrilera y petrolera mantuvieron a una gran parte de estas escuelas, mientras que los consorcios mineros trasnacionales implementaron estrategias para transferir al Estado los costos de las escuelas que financiaban.

Hasta antes del proceso de mexicanización de la minería, los consorcios mineros mantuvieron un amplio control de los espacios públicos y ocuparon el papel de proveedoras de servicios que formalmente le correspondía al Estado. Estas circunstancias no se limitaron al caso de los enclaves mineros lejanos y de difícil acceso; ya que ocurrieron aun en localidades cercanas a los centros urbanos y las capitales de los estados, como Cerro de San Pedro y Morales. Pero los alcances del proceso de mexicanización de la minería también fueron limitados, la influencia y control de las empresas sobre las comunidades mineras continuaba vigente a casi treinta años de la implementación de esta política.

El establecimiento del último plantel del estado de San Luis Potosí y documentado en el Archivo Histórico de la SEP es ejemplo de lo antes dicho, pues ocurrió en circunstancias completamente distinta a las tempranas fundaciones. La Compañía Minera las Cuevas gestionó por iniciativa propia la fundación de la escuela Artículo 123 "Las Cuevas" en agosto

\footnotetext{
${ }^{44}$ Oficio de notificación de cambio de nombre de la escuela a Artículo 123 Industrial Minera México AHSEP, DGEPET, EA123SLP, C68, E2, p. 24.

${ }^{45}$ Anuario Estadístico de los Estados Unidos Mexicanos, 1942, p. 349.
} 
de 1978 para escolarizar tanto a hijos como no hijos de sus trabajadores. La escuela "Las Cuevas" atendió a la totalidad de los niños de la localidad de Salitrera con una matrícula de 143 niños y 164 niñas; su personal docente estaba formado por un director, siete maestras y un maestro; y funcionaba en un moderno y amplio edificio construido para tal propósito por la empresa. El expediente de fundación registra que en el lugar existían los servicios de electricidad, agua potable, drenaje y asistencia médica provistos por la compañía. ${ }^{46}$ Ésta hacía hincapié en el hecho de que proveía de estos servicios y lo asentó por escrito en el expediente escolar con un claro propósito.

El Estado mexicano había realizado reformas fiscales que permitieron a los patrones transferirle los costos del financiamiento de las escuelas Artículo 123 por la vía de la deducción de impuestos. El caso de la escuela "Las Cuevas" de 1978 documenta cómo la industria minera logró endosar al erario público los gastos que realizaba en educación. La Compañía Minera las Cuevas apremiaba a la SEP para la entrega de los oficios de incorporación del plantel y el inventario legal por \$7,507,120.00 con el fin de presentarlos ante la Secretaría de Hacienda y descontarlos a los impuestos que debía pagar al erario público. A largo plazo, el propósito fundacional de obligar a al capital privado a contribuir a la educación de los hijos de sus trabajadores se cumplió en muy poca medida.

Por otra parte es fundamental establecer que las comunidades mineras no fueron receptoras pasivas, puesto que respondieron a las políticas empresariales y gubernamentales de formas diversas y frecuentemente contrarias a los intereses de esos poderes. La apropiación sociocultural de las políticas implementadas "desde arriba" con frecuencia toma rumbos inesperados puesto que siempre "transforma, reformula y excede lo que recibe" (Chartier 2003: 24). Los capitalistas extranjeros se proponían que, bajo su control, las comunidades mineras se mantuvieran ajenas a la movilización obrera de comienzos del siglo XX, pero no ocurrió así. Los trabajadores de la minería se organizaron en mutualidades, después en uniones y clubes anarquistas; después de 1917, en sindicatos y por último en el Sindicato Industrial de Trabajadores Mineros Metalúrgicos y Similares de la República Mexicana (SITMMSRM) desde 1934. Si bien estos trabajadores colaboraron con el Estado mexicano frente a los consocios extranjeros; tampoco fueron aliados incondicionales del gobierno puesto que desde las escuelas, los campos mineros y los sindicatos refutaron constantemente las políticas oficiales y lo enfrentaron abiertamente. En suma, los trabajadores mineros no resultaron metales fáciles de forjar ni para los empresarios ni para el Estado.

\section{Referencias}

\section{Archivos}

AGN

AHSEP
Archivo General de la Nación

MAV Fondo: Presidentes. Miguel Alemán Valdés

Archivo Histórico de la Secretaría de Educación Pública

EA123SLP Escuelas Artículo 123 de San Luis Potosí

\footnotetext{
${ }^{46}$ Expediente de la escuela Artículo 123 "Las Cuevas" de Salitrera, municipio de Villa de Zaragoza 19781980. AHSEP, DGEPET, EA123SLP, C74, E10.
} 


\section{Revistas y publicaciones periódicas}

E\&MJ

DOF

DDCDCEUM

SJF
McGraw-Hill, Engineering and Mining Journal, New York.

Diario Oficial de la Federación

Diario de los Debates de la Cámara de Diputados del

Congreso de los Estados Unidos Mexicanos

Semanario Judicial de la Federación

Periódico El Universal

Periódico El Heraldo de San Luis

\section{Bibliografía}

BERNSTEIN, Marvin D. (1964), The Mexican Mining Industry 1850-1950. A study of the interaction of politics, economics and technology, State University of New York, Nueva York.

BESSERER, Federico et al. (1983), El sindicalismo minero en México 1900-1952, Era, México.

BRACHET MARQUEZ, Vivianne (1996), El pacto de dominación. Estado, clase y reforma social en México (1910-1995), Colegio de México, México.

CHARTIER, Roger (2003), Espacio público, crítica y desacralización en el siglo XVIII, Los orígenes culturales de la Revolución Francesa, Gedisa, Barcelona.

CÓRDOVA, Arnaldo (1996), La revolución en crisis. La aventura del maximato, Editorial Cal y Arena, México

GAITÁN RIVERO, Mercedes (1987), El movimiento de los mineros en el alemanismo, UNAM, México.

GILLY, Adolfo (1997), El cardenismo. Una utopía mexicana, Editorial Cal y Arena, México.

GREAVES, Cecilia (2008), Del radicalismo a la unidad nacional una visión de la educación en el México contemporáneo 1940-1964, El Colegio de México, México.

HOFFMAN, Arnold (1954), "Towne Mines Corporation. A short History", manuscrito inédito en posesión particular.

INEGI (1930 y 1938), Anuarios Estadísticos de los Estados Unidos Mexicanos, Instituto Nacional de Estadística, México.

KNIGHT, Alan (1986), The Mexican Revolution, Volume1 Porfirians, Liberals and Peasants, University of Nebraska Press, USA.

KNIGHT, Alan (1994), "Cardenismo: Juggernaut or Jalopy” en Journal of Latin American Studies, Vol. 26, No. 1, Febrero de 1994, pp. 73-107. https://doi.org/10.1017/S0022216X0001885X

KNIGHT, Alan (1996), La Revolución Mexicana. Del porfiriato al nuevo régimen constitucional. Contrarrevolución y reconstrucción, Vol. II, Editorial Grijalva, México.

KRAUZE, Enrique, MEYER, Jean y REYES, Cayetano (1997), Historia de la Revolución Mexicana 1924-1928. La reconstrucción económica, El Colegio de México, México. 
LEWIS, Stephen E. (2010), “Una victoria pírrica en el México posrevolucionario: los finqueros alemanes, las escuelas Artículo 123 y la formación del Estado en la costa de Chiapas, 1934-1942", en Anuario de Estudios Americanos, 67, 2, julio-diciembre, 445-465, Sevilla, España.

LOYO, Engracia (1990), “Escuelas rurales 'Artículo 123' (1917-1940)" en Historia Mexicana, Vol. XL, octubre-diciembre de 1990, Núm. 2, El Colegio de México, México, pp. 299-336.

LOYO, Engracia (1999) “El largo camino a la centralización educativa, 1920-1992” en María del Carmen Pardo (coord.) Federalización e innovación educativa en México, El Colegio de México, México.

LOYO, Engracia (2010), "La educación del pueblo", en Tank de Esatrada, Dorothy (coordinadora), Historia mínima de la educación en México, El Colegio de México, Ciudad de México, pp. 154-187.

LOYO, Engracia y Anne Staples (2010), "Fin de siglo y de un régimen”, en Tank de Esatrada, Dorothy (coordinadora), Historia mínima de la educación en México, El Colegio de México, Ciudad de México, pp. 127-153.

MATUTE, Álvaro (1980), Historia de la Revolución Mexicana 1917-1924. Las dificultades del nuevo Estado, El Colegio de México, México.

MEDINA ESQUIVEL, René (2008), Sobrevivir en un pueblo minero. Vida cotidiana en Cerro de San Pedro, San Luis Potosí, durante la posrevolución, tesis de maestría, El Colegio de San Luis, México.

MEDINA ESQUIVEL, René (2011), "Entre apropiaciones y resistencias. Políticas culturales posrevolucionarias y vida cotidiana en dos escuelas Artículo 123 de San Luis Potosí.”, en Gamboa, Jonatan (coordinador). Arte, cultura y sociedad en San Luis Potosí en el contexto de la Revolución Mexicana. Colección San Luis de la Patria, Comisión del Bicentenario de la Independencia Nacional Centenario de la Revolución Mexicana, San Luis Potosí pp. 185-251.

MEDINA ESQUIVEL, René (2012) "Política educativa y resistencia patronal. La fundación de escuelas Artículo 123 en San Luis Potosí, 1934-1938”, en Oresta López (coordinadora), Historia y antropología de la educación II. Colección San Luis de la Patria, Comisión del Bicentenario de la Independencia Nacional Centenario de la Revolución Mexicana, San Luis Potosí, pp. 81-133.

MEDINA ESQUIVEL, René (2015) “Las escuelas Artículo 123 ¿Un dolor de cabeza para la SEP? Disputas jurídicas entre el Estado mexicano y el poder patronal, 1932-1942”, artículo de próxima publicación (enero de 2015) en la revista Secuencia.

MEDINA ESQUIVEL, René (2018), Minería y escuelas. Familias, maestros, sindicatos y empresas en Cerro de San Pedro y Morales, San Luis Potosí, 1934-1963, El Colegio de San Luis y Sociedad Mexicana de Historia de la Educación, México

MEYER, Jean, Enrique Krauze y Cayetano Reyes (1996), Historia de la Revolución Mexicana 1924-1928. Estado y sociedad con Calles, México, El Colegio de México.

ROCKWELL, Elsie (2007), Hacer escuela, hacer Estado: La educación posrevolucionaria vista desde Tlaxcala, El Colegio de Michoacán-CIESAS-Cinvestav, México.

ROMERO GIL, Juan Manuel (1991), El Boleo. Santa Rosalía, Baja California Sur. Un pueblo que se negó a morir 1885-1954, Universidad de Sonora, Hermosillo. 
SARIEGO, Juan Luis (1982), Enclaves y Minerales en el norte de México, Historia social de los mineros de Cananea y Nueva Rosita 1900.1970, CIESAS, México.

SARIEGO, Juan Luis et al. (1988), El Estado y la minería mexicana. Política, trabajo y sociedad durante el siglo XX, Fondo de Cultura Económica, México.

SARIEGO RODRÍGUEZ, Juan Luis (1994), "Minería y territorio en México: tres modelos históricos de implantación socio espacial", en Estudios Demográficos y Urbanos, Vol. 9, No. 2 (26) (May - Aug., 1994), pp. 327-337, El Colegio de México. Disponible en: http://www.jstor.org/stable/40314745.

SIERRA ALVAREZ, José (1990), El obrero soñado: Ensayo sobre el paternalismo industrial (Asturias, 1860-1917), Siglo XXI de España Editores, Madrid.

VAUGHAN, Mary Kay (2000), La política cultural en la revolución. Maestros, campesinos y escuelas en México 1930-1940, Secretaría de Educación Pública-Fondo de Cultura Económica, México. 